\title{
Capacity building of faculty and postgraduate residents of Community Medicine to streamline the assessment process in competence driven curriculum: Pilot study
}

\author{
Shrivastava, S.R. ${ }^{1}$, Chacko, T.V. ${ }^{2}$, Bhandary, S. $^{3}$
}

\section{Introduction}

Competence based medical education has been identified as the right approach to overcome the shortcomings of traditional curriculum (Touchie \& ten Cate, 2016). Competency Driven Curriculum (CDC) refers to systems of instruction, assessment, grading which depends on the fact that students have acquired the desired knowledge and skills during the education.

CDC for the postgraduate course in Community Medicine was initiated in 2016 in our institute. It was an important milestone considering that very few universities have adopted the same in India. It was soon realized that the departmental faculty and postgraduate (PG) students needed guidance for the transition to CDC.

The assessment process was subjective, unorganized, and did not involve any valid and reliable tools for the assessment of subjectspecific Entrustable Professional Activities (refer to the activities that a learner can be trusted to do once they have reached adequate competence).

${ }^{1}$ Vice Principal Curriculum, Associate Professor, Department of Community Medicine, Shri Sathya Sai Medical College \& Research Institute, Kancheepuram, India

${ }^{2}$ Dean Medical Education \& Professor Community Medicine, Believers Church Medical College \& Hospital, Thiruvalla, India

${ }^{3}$ Associate Professor, Department of Community Medicine, PAHS School of Medicine, Lalitpur, Nepal

Corresponding Author:

Dr. Saurabh RamBihariLal Shrivastava

3rd floor, Department of Community Medicine, ShriSathyaSai Medical College \& Research Institute, Ammapettai village, Thiruporur-Guduvancherry Main Road, Sembakkam Post, Kancheepuram-603108, Tamil Nadu, India

Email: drshrishri2008@gmail.com
The PG students were assessed only by their guides limiting interaction with other department faculty and even the reflective component was not explored.

\begin{abstract}
Method
In order to respond to this observation and streamline the assessment process, the departmental faculty and postgraduates were sensitized about the CDC, Entrustable Professional Activities (EPAs) and their roles in the implementation of competence driven curriculum. This sensitization process was carried out in the form of a half-day session, in which all the involved stakeholders were exposed to the various concepts in CDC and an open session was kept towards the end for discussion to clear their doubts, including their responsibilities.
\end{abstract}

Out of the 50 existing EPAs in the subject of Community Medicine, 3 were selected by consensus among faculty for PG level certification as a pilot run and appropriate 3 pre-validated workplace based assessment tools (namely, Mini-Clinical Examination Exercise, Case Based Discussion and Direct Observation of Procedural Skills) were identified for the assessment (Norcini \& Burch, 2007).

This was followed by an orientation session for PGs about the selected EPAs, their corresponding assessment tools, and the plan of assessment (viz. three times for three separate EPAs per PG student at quarterly intervals) for their certification. Feedback was obtained from the postgraduates about the session, and additional information was shared to make their understanding concrete.

Depending on the selected EPAs, rubrics of milestones were formulated for all the descriptors from grade 1 to 9 in each of the 3

DOI: http://doi.org/10.4038/seajme.v12i2.54

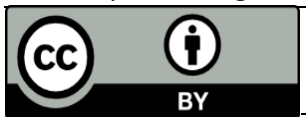

C SEAJME. This is an Open Access article distributed under the terms of the Creative Commons Attribution License (http://creativecommons.org/licenses/by/4.0/), which permits unrestricted use, distribution, and reproduction in any medium, provided the original author and source are credited. 
tools. The developed rubrics were validated both by the departmental colleagues and by the external subject experts using a 5 point Likert scale. Further, based on the received suggestions, the 3 assessment tools were modified.

All 3 PG students were assessed as a part of formative assessment in the outpatient department or wards during their clinical encounter with patients by at least 4 departmental faculties using the validated tools. After the assessment, PG students were informed about the encouraging aspects of the clinical interaction, and were given a constructive feedback about the areas for improvement. This was followed by the development of a shared learning plan to accomplish the set goals, and the students were also asked to document their reflections about each of these clinical encounters.

\section{Results}

The postgraduates reported that the assessment using rubrics made their task more precise and the received feedback from all the faculties was quite useful for them. They were more confident about the assessment process as it was systematic and objective.

Further, the PG students acknowledged that the developed rubrics acted as an indicator against which they were able to compare their learning progress. Even the assessors found the tools to be useful, systematic and objective. On compilation of the assessment scores from all the 4 department faculty members, consistent observation and scoring was reported. In the assessment form, a specific space was given to record the feedback of faculty and residents and no other specific tool was used.

\section{Conclusion}

In conclusion, as each of the departmental faculty was involved in the entire process right from the selection of EPAs till the assessment, they were quite motivated and took the onus for the entire process.

Owing to the process of capacity building, the faculty \& postgraduates are confident about the assessment processes, which is an integral part of the competence driven curriculum.

\section{Future implications}

This entire process will be expanded to more subject-specific EPAs, so that the produced doctor is a competent health professional. Further, the obtained results will be shared with the University for the Gradual Expansion of the process to other post-graduation courses running in the institute, so that the practice can be institutionalized.

In addition, the plan is to share our experience with other institutes and Universities which are on the verge of implementing competence driven curriculum in their set-up, so that they are also benefited and they get the desired guidance for streamlining their initial problems.

\section{References}

Norcini, J. \& Burch, V. (2007) Workplace-based assessment as an educational tool: AMEE Guide No. 31, Medical Teacher, 29, 9, pp. 855871.

Touchie, C. \& ten Cate, O. (2016) The promise, perils, problems and progress of competencybased medical education, Medical Education, 50, 1, pp. 93-100. 